\title{
FLEXIBILIDADE EDUCACIONAL NA CIBERCULTURA: ANALISANDO ESPAÇOS, TEMPOS E CURRÍCULO EM PRODUÇÕES CIENTÍFICAS DA ÁREA EDUCACIONAL ${ }^{1}$
}

\author{
(EDUCATIONAL FLEXIBILITY IN CYBERCULTURE: AN ANALYSIS OF SPACE, TIME AND \\ CURRICULUM IN SCIENTIFIC WORKS WITHIN THE EDUCATIONAL FIELD)
}

\author{
Daniel Mill \\ Universidade Federal de São Carlos (UFSCar), Brasil
}

\section{RESUMO}

O texto analisa os princípios da flexibilidade na educação e aborda suas implicações na qualidade do ensino e da aprendizagem na Educação a Distância (EaD). As categorias espaço, tempo e currículo são analisadas como elementos fundantes da flexibilidade, com base na virtualização das atividades humanas promovida pela emergência da cibercultura. Primeiro, foi realizado um estudo teórico sobre flexibilidade educacional, conceituando termos, caracterizando seus elementos constitutivos, evidenciando sua importância para a melhoria do ensino e da aprendizagem. Depois, como trabalho de campo, a temática foi mapeada em duas bases de publicações educacionais: 1.540 teses (doutorado) e 3.988 artigos (periódicos). Como resultado, as análises quali-quantitativas denunciaram a escassez de pesquisas voltadas para a compreensão da flexibilidade na EaD. Todavia, observamos que a estruturação de modelos pedagógicos mais adequados à nossa época requer conhecimento aprofundado da maleabilidade pedagógica: onde (espaço), quando (tempo) e como (organização curricular) ocorre o ensino-aprendizagem na cibercultura?

Palavras-chave: flexibilidade, espaço, tempo, currículo, tecnologias digitais, educação híbrida.

\begin{abstract}
This article analyzes the principles of flexibility in education and discusses their implications in the quality of teaching and learning in distance education (DE). The categories of space, time and curriculum are analyzed as founding elements of flexibility, which are based on the virtualization of human activities promoted by the emergence of cyberculture. First, we carried out a theoretical study on educational flexibility by conceptualizing terms and by characterizing their constitutive elements, In this way, we were able to highlight their importance to improve research and learning. Then, as part of the field work, we mapped out the theme based on two educational publications: 1,540 doctoral theses and 3,988 scientific
\end{abstract}


articles (journals). As a result, the qualitative-quantitative analysis showed that there was a lack of research on flexibility in DE. However, it was observed that the structure of pedagogical models, which was more appropriate to our currrent needs, requires thorough knowledge of pedagogical flexibility, including factors such as: where ( the virtual space); how (curricular organization) occurs; and how teaching and learning are involved in cyber-culture.

Keywords: educational flexibility, space, time, curriculum, digital technologies, hybrid education.

\section{CONSIDERAÇÕES INICIAIS SOBRE FLEXIBILIDADE ESPAÇOTEMPORAL E MALEABILIDADE CURRICULAR}

Pode-se dizer que a Educação a Distância (EaD) constitui-se em esforços para flexibilizar a tradicional forma de organização da educação presencial. As várias formas de configuração da $\mathrm{EaD}$ representam novas formas de estabelecer tempos e espaços de aprendizagem e possibilidades de organização curricular mais maleáveis. Isto está na base da noção de educação virtual e, por isso, trata-se de um assunto crucial e, ainda assim, muito pouco conhecido até o momento.

Mesmo numa análise superficial da sociedade atual, percebemos influências das tecnologias digitais de informação e comunicação (TIDIC) em quase todas as atividades humanas. A literatura trata de uma convergência midiática sem precedentes, resumida na fusão das telecomunicações com a informática (telemática). Trata também das implicações que tal convergência traz, de diferentes modos, às pessoas. Podemos dizer que as tecnologias digitais afetaram quase todas as áreas do conhecimento e reorganizou praticamente todos os espaços e tempos de convivência ou exploração humana. Na base dessas transformações está o redimensionamento dos espaços e tempos (Harvey, 2009) tradicionalmente estabelecidos em períodos anteriores à cibercultura. As TDIC possibilitaram-nos experiências diferenciadas e novas noções em relação ao lugar/espaço e ao horário/momento/tempo de socialização, com implicações plurais, de natureza cultural, social, política, ambiental, geográfica, artística, trabalhista, etc.

Esse cenário apresenta aos educadores alguns desafios. Na EaD, por exemplo, há ambientes virtuais de aprendizagem em que o ensino-aprendizagem ocorre numa sala de aula configurada de uma forma diferenciada da tradicional: a sala de aula virtual não existe com a mesma caracterização física tradicional (claridade, ventilação, mesa de professor, mesmo conforto, mesmas carteiras de estudantes enfileiradas, janelas etc.). Então, o que é uma sala de aula?

Ademais, possíveis respostas a esta questão devem considerar que, na educação virtual, perdem a centralidade aqueles lugares tradicionalmente chamados de 
"salas de aula" - inclusive porque já não há mais os horários/momentos aos quais denominava-se como "aulas" (Mill et al., 2012). Desta forma, parece mais coerente perguntar, atualmente: o que vem a ser a nova sala de aula? Isto é, o que é o lócus configurado como ambiente de ensino-aprendizagem na educação virtual?

As particularidades da educação virtual põem em questão a lógica tradicional e a organização espaçotemporal do ensino-aprendizagem (Mill, 2012). A adoção de tecnologias digitais constitui, por si só, uma peculiaridade essencial, da qual outras tantas podem decorrer. Por exemplo, questiona-se: em que momentos o estudante aprende de verdade? Aprendemos apenas numa sala de aula? Onde um aluno aprende é o lugar em que todos melhor aprendem? Todos nós aprendemos ao mesmo tempo? Todos os alunos aprendem da mesma forma? Essas questões emergem no bojo da virtualização da aula e da sala de aula, em que novas configurações são possíveis e a flexibilidade pedagógica pode tomar forma.

Geralmente, a organização do ensino-aprendizagem, com articulações entre estudante-professor, estudante-conteúdos e professor-conteúdos, ainda é válida, mas sua estrutura deve agora ser estabelecida em novas bases, com espaços, tempos, relações sociais e componentes curriculares redimensionados pelas TDIC. Podese dizer também que há implícitas nessas tecnologias as possibilidades de maior flexibilidade, liberdade e mobilidade para os envolvidos com a educação. Como afirmam Frago e Escolano (2001, p.62), a escola ocupa um espaço e um lugar: um espaço projetado ou não para tal uso e um lugar por ser um espaço ocupado e utilizado. Assim, questiona-se como uma "escola virtual" pode ser percebida, atualmente, por educadores e estudantes.

Entendemos que a compreensão dos lugares e momentos da educação deve partir de duas bases:

- a noção de tempo e a relação que os homens estabelecem com ele variam de acordo com o estágio de desenvolvimento em que se encontram os grupos humanos (Elias, 1998). Ou seja, a experiência do tempo não é necessariamente a mesma para todos os grupos humanos.

- a sala de aula pode ser entendida apenas como um lugar percebido, construído socialmente e simbolicamente. Espaços com significados e representações de espaços, pois a percepção é um processo cultural (Frago e Escolano, 2001).

Essas bases sugerem uma interpretação não apenas da disposição material dos espaços, como também de sua dimensão simbólica - o valor didático do símbolo 
constitui um aspecto a mais da dimensão educativa do espaço. Esse mesmo entendimento é válido para todos os outros espaços e tempos da educação virtual. Por isso mesmo, podemos inferir que o espaço de ensino-aprendizagem da educação virtual é apenas uma configuração distinta dos ambientes de aprendizagem tradicionais. Reconfigurados dessa forma, os novos espaços e tempos adéquam-se às novas necessidades e, ou, ao estágio de desenvolvimento tecnológico. Emergem daí novas possibilidades de experimentação do tempo, donde destacamos, especialmente, aquelas ligadas à flexibilização de "tudo": uma sala de aula em que o arranjo "material" não obedece ao espaço material ou geográfico, como vimos. Uma sala de aula que está em todo lugar e a qualquer momento... Afinal, a flexibilidade temporal possibilitou a dobra do espaço; ou melhor, um ciberespaço, quase celestial: onipresença, onisciência e onipotência.

É nesse cenário, de intensa incorporação das tecnologias digitais no âmbito educacional, que se estabelece a problemática que buscamos responder neste texto: como tratar da flexibilidade pedagógica, em termos de espaciais, temporais e de organização curricular? A seguir, faremos um primeiro movimento em busca de respostas a esta questão, passando pela caracterização e definição da temática.

\section{FLEXIBILIDADE EDUCACIONAL: UMA BREVE CONCEITUAÇÃO}

Analisando a proposta educacional da UOC (Universidade Aberta da Catalunha - Espanha), Tubella et al. (2011, p.3) observam que uma das coisas que tem marcado as universidades (virtuais ou não) tem sido a busca por um modelo educacional próprio, flexível e dinâmico, completamente baseado na virtualização da educação. Trata-se de assegurar aos estudantes a aprendizagem de forma semelhante, mas respeitando suas diferenças. Isto agrega valor ao processo e garante habilidades digitais aos alunos, pelo redesenho de espaços, recursos e dinâmicas propícios à aprendizagem. Mais importante ainda, num modelo de educação flexível, as atividades acadêmicas são orientadas para estudantes e para a aprendizagem; ou seja, o foco é a aprendizagem, em vez do ensino. Acreditamos que essas bases contribuem para o acesso e permanência de estudantes em cursos de nível superior.

Há dez anos, o Fórum Nacional de Pró-Reitores de Graduação das Universidades Brasileiras (ForGRAD, 2003) estabeleceu uma discussão e gerou um documento sobre concepções e implementação da flexibilidade curricular. Esse documento aponta diretrizes e orientações gerais como referências para a efetivação de ações de flexibilização no âmbito dos projetos pedagógicos dos cursos de graduação, respeitadas as particularidades e autonomia de cada universidade. 
Todavia, na educação presencial, isso sempre foi (e continua sendo) um imenso desafio para gestores e docentes, pois essa flexibilidade pressupõe liberdade e mobilidade estudantil em termos de espaço, tempo e organização curricular - o que não é facilmente implementável com as possibilidades espaçotemporais ou pedagógicas da educação tradicional. Entendemos que essa flexibilidade educacional está mais tangível na educação virtual, pelo uso intensivo das tecnologias digitais, no âmbito da cibercultura.

Para começar a discutir esse assunto, é importante esclarecer qual a noção de flexibilidade está sendo adotada neste texto: o que é flexibilidade? Sobre que tipo de flexibilidade este texto traz reflexões?

Sobre a definição de flexibilidade em geral, não há muito por revelar. É um termo simples e dicionarizado há muito tempo. Conforme o dicionário Houaiss (2001), entre os significados do termo, flexibilidade é a qualidade daquilo que é flexível que, por sua vez, significa aquilo que se dobra ou verga facilmente sem se quebrar, que se acomoda suavemente ou sem resistência. O termo vem do latim "flexibilis" (dobrável), derivado de "flectere" (dobrar). Assim, flexibilidade educacional pode ser entendida pelas possibilidades de (re)organização da educação, em função de diversos interesses ou necessidades. A capacidade de adaptação da proposta de formação aos perfis e interesses dos estudantes está, portanto, no centro da noção de flexibilidade educacional que está sob nosso olhar neste texto.

Entre os cuidados estabelecidos pelos referenciais de qualidade para a educação superior a distância (Brasil, 2007), a instituição deverá, no projeto político e pedagógico do curso, assegurar a flexibilidade no atendimento ao estudante, oferecendo horários ampliados para o atendimento tutorial. Fica evidente o foco na flexibilidade temporal, sem atenção à maleabilidade espacial e curricular.

Existem diversas formas de organização do currículo, podendo ser mais flexíveis ou mais rígidas/tradicionais. Independente das formas possíveis de flexibilização educacional, este texto tem particular interesse no tipo particular de flexibilidade educacional marcado pela maleabilidade espaçotemporal e curricular. Em especial, discutiremos as possibilidades dessa flexibilidade no âmbito da Educação a Distância, que embora tenha sua base/estrutura semelhante à da educação presencial, ela mesma representa em si um movimento pela flexibilidade pedagógica. Podemos dizer, inclusive, que a diferença entre as duas modalidades está nessa maior ou menor flexibilidade. Assim, faz-se necessário esclarecer as noções de flexibilidade espacial, flexibilidade temporal e flexibilidade da organização curricular. Enfim, o que estamos entendendo por flexibilidade na EaD? 
Como já indicamos, a flexibilidade na educação pode ser entendida, no mínimo, em três perspectivas complementares e essenciais: foco nos espaços, nos tempos e na organização curricular. Pensar na flexibilidade educacional exige acionar certos conceitos e coisas: ensino, aprendizagem, avaliação, metodologia, didática, organização, planejamento, eficiência e objetivos (Silva, 2004). Todos esses elementos articulam-se com as categorias espaço, tempo e currículo.

Quando tratamos da flexibilidade espacial na educação, estamos interessados, entre outros elementos, nas possibilidades de mobilidade geográfica, limitações físicas e de deslocamento dos estudantes, organização de ambientes pedagógicos (laboratórios, bibliotecas ou salas de aula, por exemplo). As noções de lugar de ensino-aprendizagem são colocadas em jogo quando consideramos o como e o porque flexibilizar os espaços escolares ou acadêmicos da educação presencial, historicamente constituídos.

Pensar na flexibilidade dos tempos educacionais implica considerar horários e momentos de convivência/relações entre educadores-educandos-educandosconteúdos-conteúdos-educadores, nas possibilidades de personalização dos estudos, na (as)sincronicidade dos estudos, nos aspectos logísticos e fluxos de materiais e pessoas, na organização temporal dos ambientes pedagógicos (aulas, intervalos, horários de disciplinas, atividades físicas, semestralidade, séries, por exemplo). As noções de momentos de ensino-aprendizagem são colocadas em jogo quando consideramos o quando e o porque flexibilizar os tempos escolares ou acadêmicos da educação presencial, historicamente constituídos.

O supracitado documento do ForGRAD (2003) indica que a flexibilidade educacional (curricular, em particular) é essencial para configurar melhores propostas de formação, pois tem sido motivada pela necessidade de adequar o processo de educacional às dinâmicas do conhecimento, da ciência e da prática profissional.

O entendimento tomado no documento é que a flexibilização curricular é algo que se impõe nas reformas curriculares dos cursos de graduação face às exigências das rápidas transformações socioeconômicas, geopolíticas, culturais e tecnológicas que vêm ocorrendo na sociedade, com seus desdobramentos gerais e particulares na educação, em especial, no ensino superior (ForGRAD, 2003).

A flexibilidade curricular pode ser entendida como uma forma de organização do conhecimento, cuja matriz curricular não é rígida. A formação é, portanto, entendida como um percurso com possibilidades alternativas de trajetórias. A flexibilidade 
curricular busca a promoção de maior liberdade ao estudante e educadores para definição e desenvolvimento das atividades da formação.

Sabendo que a organização pedagógica de uma matriz curricular pode ser mais rígida/inflexível ou mais dinâmica/flexível, neste texto pretendemos lançar luz na capacidade ou limitação da modalidade de Educação a Distância adotar uma proposta educacional mais maleável e adequada a sujeitos plurais, imersos em contextos dinâmicos, complexos e em constante transformação. Como veremos, a flexibilidade pedagógica na $\mathrm{EaD}$ está diretamente relacionada às potencialidades da $\mathrm{EaD}$ atender, de modo diverso e múltiplo, a estudantes situados em lugares distantes dos grandes centros de formação acadêmica e impossibilitados de frequentar as aulas em momentos definidos pela academia. Ou seja, flexibilidade pedagógica representa grandes desafios aos educadores para pensar propostas de ensino-aprendizagem com momentos e lugares mais adequados aos estudantes, que terão maior liberdade para realizar as atividades em termos de quando, como e onde estudar.

\section{BREVE CONTEXTUALIZAÇÃO: A CIBERCULTURA COMO LÓCUS DE OBJETIVAÇÃO DA FLEXIBILIDADE EDUCACIONAL}

Considerando a emergência de novas maneiras dominantes pelas quais experimentamos o tempo e o espaço, Harvey (2009) afirma que a sociedade está vivendo uma mudança abissal nas práticas culturais, políticas e econômicas. Seja pela "compressão" espaçotemporal ou pela "necessidade" de maior flexibilidade nos espaços e tempos sociais, essa mudança abissal vincula-se ao estágio de desenvolvimento tecnológico atingido nesse século - em particular as tecnologias digitais de informação e comunicação (TDIC). Instala-se uma cultura "do acesso" e "do aqui-agora", que tem suas bases na flexibilidade ou fluidez dos espaçotempos da cibercultura. A instantaneidade parece ser mais valorizada do que a maturidade, a tradição ou o planejamento.

Jamais outra tecnologia possibilitou tamanha flexibilidade nos tempos e espaços de convivência (trabalho, lazer, estudos etc.) como a internet e essa potencial flexibilidade também constitui elementos de sedução para a incorporação das TDIC nas atividades em geral.

O desenvolvimento das tecnologias de informação e comunicação permite cada vez mais o rompimento de limitações temporais e espaciais. Muitos são aqueles que, graças a esta flexibilidade de nossa relação com o tempo e com o espaço, sonham com uma sociedade organizada com uma nova distribuição dos horários de trabalho, deixando a parte bela da vida ao lazer e à família (Rossel et al., 1998, p.267). 
Observa-se que o rompimento de limitações temporais e espaciais, fruto do desenvolvimento das TDIC, estimula o aumento dos sonhadores com horários e locais flexíveis de trabalho ou para o desenvolvimento de outras atividades. Essa característica afetou diretamente o campo educacional, a exemplo da recente expansão e valorização da EaD. Podemos dizer que os diferentes tipos de configuração desta modalidade (ensino a distância, aprendizagem aberta, educação virtual, u-learning, m-learning, educação online, b-learning etc.) são formas distintas de organização dos tempos, espaços e matriz curricular, como forma alternativa à tradicional proposta da educação presencial. A EaD traz consigo esse princípio: flexibilizar o modelo tradicional para democratizar o conhecimento, por meio de novas possibilidades de formação. Nessas bases, cabe questionar quão flexível tem sido a EaD e, também, quais tipos de flexibilidade essa modalidade dá conta.

Em comparação à educação tradicional, a configuração da educação virtual evidencia aspectos positivos peculiares. Por exemplo, a flexibilidade dos espaços e tempos de ensino e aprendizagem, a autonomia para organizar os próprios locais e horários de realização das atividades, a possibilidade/estímulo de letramento digital, a possibilidade de tempo mais livre, o aumento das possibilidades de a mulher ingressar no mercado de trabalho remunerado enquanto acompanha a educação e o crescimento dos filhos etc. Enfim, à educação virtual agregam-se práticas e conceitos espaçotemporais peculiares e marcados pela fluidez, flexibilidade e virtualidade literais. Apesar das perversidades ${ }^{2}$ aí implícitas, trata-se de um elemento de extrema riqueza em diversas perspectivas. Ao analisar modelos flexíveis de aprendizagem, Tubella et al. (2011) afirmam que "flexibilidade" foi uma das palavras mais usadas/ desejadas pelos estudantes virtuais (sujeitos da pesquisa), com destaque para a necessidade de combinar os estudos com o trabalho.

Outro dado interessante da investigação é que ter tempo para se envolver em várias atividades é muito importante e valorizado para os jovens. Esses jovens justificam que escolheram os estudos online pela flexibilidade oferecida pelo modelo pedagógico da educação virtual em termos de horários e atividades, o que torna possível para os alunos a estudar e trabalhar, estudar e se envolver em uma atividade de lazer, esporte, etc.; ou simplesmente estudar coisas de interesse que não são oferecidas em sua região (Tubella et al., 2011, p.9).

Como o foco deste texto está nas novas possibilidades de organização curricular e espaçotemporal particular da educação virtual, interessam aqui as possíveis configurações do sistema logístico de EaD - novas possibilidades de circulação de materiais didáticos e fluxos de informações -, o que influencia diretamente os custos de produção e distribuição de cursos, o modelo de atendimento aos estudantes, a concepção pedagógica da formação, a noção de democratização do conhecimento, 
de personalização da formação e de flexibilidade temporal, espacial e curricular, entre outros aspectos. Ou seja, este texto explora a Educação a Distância como uma modalidade de educação geralmente considerada uma forma alternativa e complementar (mas não necessariamente substitutiva, superior ou inferior) para formação do cidadão (brasileiro e do mundo), com ricas possibilidades pedagógicas e grandes potenciais para a democratização do conhecimento, decorrentes do seu princípio de flexibilidade temporal, espacial e curricular. Assim, do ponto de vista dos gestores da EaD cabe questionar: qual a melhor configuração para o ensinoaprendizagem na atualidade? Como configurar tempos, espaços e organização curricular de modo adequado para atender aos estilos de aprendizagem de cada estudante, submetido a determinadas condições particulares de vida?

Do ponto de vista prático, diversos tipos de configuração já foram propostos para a EaD, como tentativa de efetivação do princípio da flexibilidade. Atualmente, temos iniciativas de $\mathrm{EaD}$ mais tradicionais (baseados em materiais impressos ou audiovisuais, por exemplo) e iniciativas mais inovadoras ou projetivas (como propõem os adeptos do e-learning, b-learning, m-learning ou u-learning). Mais tradicionais ou mais inovadoras, as experiências de EaD sempre representam um esforço para romper com barreiras espaçotemporais ou limitações pedagógicas da matriz curricular mais típicas da educação presencial.

Na perspectiva da organização curricular, os educadores (gestores e docentes) responsáveis pela organização de programas de formação buscam entender o perfil do estudante e, assim, preparar propostas pedagógicas mais adequadas aos seus tempos e espaços. Como afirmou Mill (2012), a educação está relacionada com tempos e espaços numa firme amálgama e a história da educação nos indica que:

as melhores estratégias de ensino-aprendizagem buscaram organizar o tempo em blocos diários, semanais, mensais ou anuais, em fases da vida (infância, juventude, adultos etc.), em etapas ou níveis de conhecimento (fundamental, médio, superior etc.) e o espaço em prédios e outras construções (como escolas, universidades etc.), distribuídos em salas de aula, biblioteca, laboratórios e outros ordenamentos espaciais (p.106).

Isto vale para educação presencial ou a distância. O que muda de uma modalidade educacional para outra são as formas de organização espaçotemporal. Por isso e pela própria natureza de presença e distância, as noções de tempo e de espaço têm sido tão presentes nas discussões sobre ensinar e aprender neste século XXI. De todo modo, vale resgatar em Doctors (2003) e Santos (1999) a noção de que é no tempo e no espaço que a vida acontece; é no tempo que as relações e movimentos se dão e é o espaço que acolhe essas ações do movimento, das pessoas... enfim, é o tempo e 
o espaço que acolhem a história e a vida. A educação presencial e a EaD são apenas configurações possíveis para tempos e espaços percebidos, de modo a acolher a história e a vida nos tempos atuais, marcados por intensas influências das TDIC.

No bojo dessas possibilidades técnico-pedagógicas típicas da cibercultura, emergem-se as condições necessárias para uma educação virtual, desmaterializada, flexível, acessível e democrática. Os tempos ciberespaciais, especialmente a nova noção de duração e de lugar, criam novas possibilidades relacionais que se configuram como campo fértil para um ensino-aprendizagem mais rico e democrático - gerando movimentos de cooperação/colaboração e de interação/interatividade, que estão no centro das relações em geral e, em particular, das relações de ensino-aprendizagem. Assim, o cenário propiciado pelas TDIC, tão favorável à EaD, articula-se com um movimento para democratizar o acesso à educação de qualidade e a estruturação de experiências de EaD para atendimento à crescente demanda por cursos em nível superior no Brasil. A dinâmica decorrente dessas possíveis e complexas relações sociais na cibercultura redimensionou as tradicionais bases espaçotemporais das relações humanas, potencializando as oportunidades de formação de sujeitos e grupos geograficamente distribuídos por todo o mundo.

Em suma, as possibilidades dos tempos ciberespaciais estimulam novas oportunidades pedagógicas e marcam, inclusive, a própria definição de Educação a Distância. Do ponto de vista da terminologia da EaD e partindo da concepção mais democrática da modalidade, buscamos em Moore e Kearskey (2008) uma sintética definição para EaD, muito embora não possamos considerar educação e aprendizagem como sinônimos:

Educação a distância é o aprendizado planejado que ocorre normalmente em um lugar diferente do local do ensino, exigindo técnicas especiais de criação do curso e de instrução, comunicação por meio de várias tecnologias e disposições organizacionais e administrativas especiais (p.2).

Observa-se que o uso intensivo de tecnologias digitais e a separação física (espaço-temporal) entre aluno e professor são prerrogativas básicas da EaD. Os sistemas de EaD têm organizado seu sistema logístico, grosso modo, em dois tipos: organização de tipo virtual ou organização de tipo central-polos. Do ponto de vista da flexibilidade educacional, em termos de espaço, tempo e organização curricular, esta caracterização da $\mathrm{EaD}$ em dois tipos logísticos é importante, pois a organização de tipo virtual é imensamente mais flexível e capaz de atender aos estilos de aprendizagem dos estudantes do que a EaD de tipo central-polos. Todavia, esse último tipo é, ainda, mais flexível do que a organização da educação presencial. 
Além de maior colaboração e interatividade, os espaços e tempos ciberculturais trouxeram possibilidades de personalização e maior flexibilidade - ambas de extrema importância para uma proposta de educação condizente com o contexto contemporâneo. A maior flexibilidade temporal e espacial possibilita maior flexibilidade pedagógica e curricular, o que está na base de uma formação personalizada, capaz de atender às condições de cada educando: seus interesses, seus estilos de aprendizagem, suas necessidades particulares, seus horários e lugares de estudo, etc. Ao menos em teoria, a cibercultura possibilita, finalmente, uma desejada educação para todos e, ao mesmo tempo, para cada indivíduo. A formação aberta, flexível e personalizada está na base das promessas da EaD e da noção de democratização do conhecimento - o que deve ser almejado pelos gestores de um sistema de EaD.

Sendo uma temática tão importante e central na discussão sobre o ensinoaprendizagem de qualidade, perguntamo-nos: que atenção a flexibilidade educacional (espaçotemporal e pedagógica) tem recebido de pesquisadores? Buscando resposta a esta inquietação, realizamos uma pesquisa de base documental-bibliográfica em teses e artigos da área educacional, quando sondamos quali-quantitativamente as publicações voltadas para a temática flexibilidade educacional.

\section{O QUE INDICA A PRODUÇÃO CIENTÍFICA SOBRE A TEMÁTICA: UMA ANÁLISE DE TESES E ARTIGOS}

Para fundamentar o argumento sobre o modo como a flexibilidade na EaD tem sido explorada em pesquisas e publicações científicas, apresentamos abaixo uma breve análise da temática em periódicos da área de educação e em teses de doutorado defendidas em Programas de Pós-Graduação em Educação. Apesar da importância do tema flexibilidade na EaD, temos por hipótese que ainda são poucas as produções científicas na área. A evolução e expansão pelas quais passou a $\mathrm{EaD}$ nos últimos anos e a sua crescente importância como modalidade de formação tornaram-na um campo fértil para investigações, mas ainda não suficientemente compreendido em diversos aspectos, incluindo aí a perspectiva da flexibilidade. Para confirmar ou refutar a nossa hipótese, buscamos elementos que respondam os questionamentos: Como a temática flexibilidade na $\mathrm{EaD}$ tem sido tratada nos últimos anos? Quantitativamente, quão representativa é a produção realizada sobre $o$ assunto? A flexibilidade na educação em geral tem recebido atenção em pesquisas e teses e artigos da área educacional?

Recentemente o Grupo de Estudos e Pesquisas sobre Inovação em Educação, Tecnologias e Linguagens (Horizonte) organizou duas bases de dados de periódicos 
e teses, como resultado parcial de pesquisas sobre $\mathrm{EaD}$ e docência virtual. Para a primeira base de dados (Base Teses), o Grupo Horizonte coletou e catalogou 1.540 teses de doutorado, defendidas em oito importantes Programas de Pós-Graduação em Educação (PPGE) brasileiros ${ }^{3}$. Foi registrado um total de 6.829 termos-chave para o grupo de teses catalogadas. Na segunda base de dados (Base Periódicos), o Grupo Horizonte catalogou e organizou 3.988 artigos, publicados em 11 periódicos ${ }^{4}$ brasileiros qualificados com A1 ou A2 pelo Qualis Capes. No total, esses artigos possuem 14.809 termos-chave. Utilizamos essas duas bases para identificar quais trabalhos têm sido publicados com interesse direto ou indireto na temática Flexibilidade na Educação a Distância ${ }^{5}$.

\section{Aspectos metodológicos e procedimentais}

Assim, do ponto de vista metodológico, estabelecemos a seguinte estratégia: a) catalogamos teses e artigos, considerando títulos, autores, resumos, palavras-chave e informações gerais (editora, ano, cidade, revista etc.); b) levantamos possíveis descritores tangentes à flexibilidade na $\mathrm{EaD}$; c) categorizamos as palavras-chave dos trabalhos com base na literatura e em pesquisas em cinco blocos; d) classificamos e analisamos quantitativamente os trabalhos de acordo com seus termos-chave; e) selecionamos e analisamos qualitativamente, com base nos títulos e resumos, os trabalhos que mais se aproximaram da temática flexibilidade na EaD. De posse desta análise quali-quantitativa das produções científicas da área, articulamos os resultados com a discussão mais geral do nosso texto.

Como vimos nas seções anteriores deste texto, o entendimento integral do processo de flexibilidade passa por elementos diversos e esta flexibilidade só pode ser efetiva se agregar três tipos de flexibilidade, quais sejam: flexibilidade espacial, flexibilidade temporal e flexibilidade pedagógica (Figura 1). Isto é, para que uma proposta de ensino-aprendizagem possa ser considerada de fato flexível, os seus tempos e espaços e a sua estrutura curricular deve ser deveras dinâmica, maleável e fluida. Nesse sentido, buscamos termos típicos do campo educacional que podem estar relacionados a esses três aspectos da flexibilidade (espaço, tempo e pedagogia). 


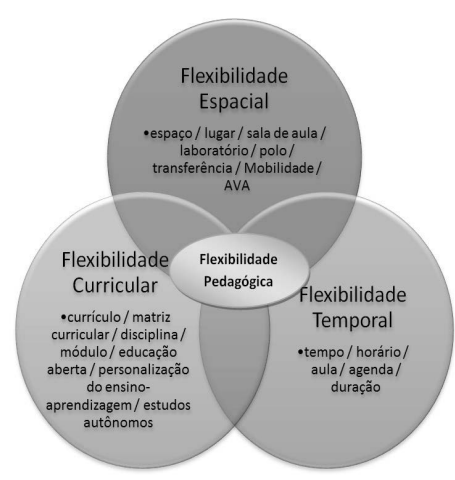

Figura 1. Categorias básicas da flexibilidade educacional, considerando uma proposta mais adequada aos horários e lugares de vida dos estudantes

Para buscar essa produção científica relacionada à temática flexibilidade na $E a D$, detalhamos cada uma das três categorias da Figura 1, mapeando possíveis descritores ou palavras-chave componente daquele bloco. Assim, organizamos cinco blocos de termos ou descritores que, em conjunto, quais sejam:

- Bloco A: Flexibilidade em geral - busca por termos contendo alguma das chaves: flexível / flexibilidade.

- Por ser o termo central, é importante observar se algum trabalho traz no título ou nas palavras-chave o radical flex*.

- Bloco B: Modalidade de Educação a Distância e seus diferentes tipos de configuração ou "sinônimos" - busca por termos contendo alguma das chaves: Educação a Distância (EaD) / ensino a distância / educação virtual / educação online / aprendizagem a distância / e-learning (aprendizagem a distância) / u-learning (aprendizagem ubíqua) / b-learning (aprendizagem híbrida) / m-learning (aprendizagem com mobilidade).

- Por ser o campo maior da investigação, justifica compreender o contexto da modalidade, evidenciando a importância dada por pesquisadores ao tema $\mathrm{EaD}$ em geral, para depois relaciona-lo aos aspectos da flexibilidade.

- Bloco C: Flexibilidade Espacial - busca por termos contendo alguma das chaves: espaço / lugar / sala de aula / laboratório / polo / transferência / Mobilidade / AVA (ambiente virtual de aprendizagem). 
- Como observamos em seções anteriores, a flexibilidade espacial é o primeiro passo para dinamizar o ensino-aprendizagem e liberar estudantes e professores para realizar suas atividades mais livremente. Assim, é importante observar a ocorrência de termos relacionados aos espaços tradicionais ou inovadores.

- Bloco D: Flexibilidade Temporal - busca por termos contendo alguma das chaves: tempo / horário / aula / agenda / duração / movimento.

- Como quarta dimensão do espaço e responsável pelo movimento e vida dos sujeitos e objetos do ambiente, o tempo é em si motivo de flexibilidade. Sem considerar o tempo, não há flexibilidade efetiva. Por isso, é necessário verificar quais trabalhos tratam de tempos e dinâmica escolares.

- Bloco E: Flexibilidade Pedagógica - busca por termos contendo alguma das chaves: currículo / matriz curricular / disciplina / módulo / educação aberta / personalização do ensino-aprendizagem / estudos autônomos.

- Por último e não menos importante, a flexibilidade do ensinoaprendizagem ocorre efetivamente quando temos uma proposta pedagógica que a possibilite. Assim, é essencial identificar e analisar os trabalhos que tratam de aspectos da flexibilidade pedagógica, especialmente em termos de matrizes e componentes curriculares.

Enfim, consultamos ocorrências de cada termo de cada bloco como estratégia auxiliar para analisar a temática central flexibilidade na EaD. Consideramos que esses cinco blocos são representativos da temática central de modo amplo ou específico. A busca foi feita tanto nas palavras-chave dos artigos e teses, quanto nos títulos dos trabalhos. A Tabela 1 apresenta as quantidades de termos localizadas nas Bases consultadas.

\begin{tabular}{|c|c|c|c|c|c|}
\hline & \multirow[b]{2}{*}{ No termo ou título contém... } & \multicolumn{2}{|c|}{ Base Periódicos } & \multicolumn{2}{|c|}{ Base Teses } \\
\hline & & $\begin{array}{c}\text { Termos- } \\
\text { chave } \\
(14.809)\end{array}$ & $\begin{array}{l}\text { Títulos } \\
\text { (3.988) }\end{array}$ & $\begin{array}{c}\text { Termos- } \\
\text { chave } \\
(6.829)\end{array}$ & $\begin{array}{l}\text { Títulos } \\
\text { (1.540) }\end{array}$ \\
\hline \multirow{2}{*}{\begin{tabular}{l|}
$\varangle$ \\
8 \\
0 \\
0 \\
0
\end{tabular}} & Flexível & 3 & o & o & o \\
\hline & Flexibilidade & 3 & 4 & o & o \\
\hline
\end{tabular}




\begin{tabular}{|c|c|c|c|c|c|}
\hline & \multirow[b]{2}{*}{ No termo ou título contém... } & \multicolumn{2}{|c|}{ Base Periódicos } & \multicolumn{2}{|c|}{ Base Teses } \\
\hline & & $\begin{array}{l}\text { Termos- } \\
\text { chave } \\
(14.809)\end{array}$ & $\begin{array}{l}\text { Títulos } \\
\text { (3.988) }\end{array}$ & $\begin{array}{c}\text { Termos- } \\
\text { chave } \\
(6.829)\end{array}$ & $\begin{array}{l}\text { Títulos } \\
\text { (1.540) }\end{array}$ \\
\hline \multirow{9}{*}{$\begin{array}{c}n \\
0 \\
0 \\
0 \\
n\end{array}$} & Educação a Distância (EaD) & $31(1)$ & 17 & $26(1)$ & 12 \\
\hline & Ensino a distância & $2(1)$ & o & $18(1)$ & o \\
\hline & Educação virtual & 0 & $\mathrm{O}$ & $\mathrm{O}$ & o \\
\hline & Educação online & $2(1)$ & 0 & $3(1)$ & 1 \\
\hline & Aprendizagem a distância & 0 & o & $\mathrm{o}$ & o \\
\hline & e-learning (aprendizagem a distância) & $3(1)$ & 0 & $1(1)$ & $\mathrm{o}$ \\
\hline & u-learning (aprendizagem ubíqua) & 0 & 0 & 0 & 0 \\
\hline & b-learning (aprendizagem híbrida) & o & o & $1(1)$ & 1 \\
\hline & $\begin{array}{lll}\begin{array}{l}\text { m-learning } \\
\text { mobilidade) }\end{array} & \text { (aprendizagem } & \text { com } \\
\end{array}$ & 0 & o & o & o \\
\hline \multirow{9}{*}{$\begin{array}{l}0 \\
0 \\
0 \\
0 \\
09\end{array}$} & Espaço & $27(22)$ & 53 & $17(11)$ & 26 \\
\hline & Lugar & $9(5)$ & 26 & o & 10 \\
\hline & Sala de aula & $15(7)$ & 26 & $15(6)$ & 23 \\
\hline & Laboratório & $6(5)$ & 10 & $3(3)$ & 3 \\
\hline & Polo & 0 & o & 0 & o \\
\hline & Transferência & $3(3)$ & 2 & $1(1)$ & 3 \\
\hline & Mobilidade & $8(4)$ & 3 & $2(2)$ & 1 \\
\hline & Ambiente & $36(22)$ & 34 & $34(11)$ & 23 \\
\hline & $\begin{array}{lll}\text { AVA (ambiente virtual de } \\
\text { aprendizagem) }\end{array}$ & $9(3)$ & 6 & $12(1)$ & 5 \\
\hline \multirow{5}{*}{$\begin{array}{c}0 \\
0 \\
0 \\
0 \\
\oplus\end{array}$} & Tempo & $40(16)$ & 84 & $11(7)$ & 25 \\
\hline & Horário & $1(1)$ & 1 & 0 & 0 \\
\hline & Aula & $9(7)$ & 31 & 4 & 16 \\
\hline & Agenda & $2(2)$ & 20 & $\mathrm{O}$ & $\mathrm{O}$ \\
\hline & Duração & 0 & 1 & 0 & 1 \\
\hline
\end{tabular}




\begin{tabular}{|c|c|c|c|c|c|}
\hline & \multirow[b]{2}{*}{ No termo ou título contém... } & \multicolumn{2}{|c|}{ Base Periódicos } & \multicolumn{2}{|c|}{ Base Teses } \\
\hline & & $\begin{array}{l}\text { Termos- } \\
\text { chave } \\
(14.809)\end{array}$ & $\begin{array}{l}\text { Títulos } \\
\text { (3.988) }\end{array}$ & $\begin{array}{c}\text { Termos- } \\
\text { chave } \\
(6.829) \\
\end{array}$ & $\begin{array}{l}\text { Títulos } \\
\text { (1.540) }\end{array}$ \\
\hline \multirow{7}{*}{$\begin{array}{l}\text { 되 } \\
\text { ठ } \\
0 \\
0\end{array}$} & Currículo & $129(21)$ & 48 & $54(8)$ & 21 \\
\hline & Matriz curricular & $\mathrm{o}$ & $\mathrm{o}$ & $\mathrm{o}$ & $\mathrm{o}$ \\
\hline & Disciplina & $63(21)$ & 46 & $28(11)$ & 26 \\
\hline & Módulo & $\mathrm{O}$ & $\mathrm{O}$ & $\mathrm{O}$ & $\mathrm{O}$ \\
\hline & Educação aberta & 0 & 0 & 0 & $\mathrm{o}$ \\
\hline & $\begin{array}{l}\text { Personalização do ensino- } \\
\text { aprendizagem }\end{array}$ & o & o & o & o \\
\hline & Estudos autônomos & 0 & 0 & 0 & 0 \\
\hline & $\begin{array}{r}\text { Somatório } \\
\text { (valor absoluto e percentual em relação à } \\
\text { quantidade de trabalhos da respectiva base) }\end{array}$ & $\begin{array}{c}401 \\
(10 \%)\end{array}$ & $\begin{array}{c}412 \\
(10,33 \%)\end{array}$ & $\begin{array}{c}230 \\
(14,9 \%)\end{array}$ & $\begin{array}{c}197 \\
(12,79 \%)\end{array}$ \\
\hline
\end{tabular}

Tabela 1. Produção de textos científicos (teses e artigos) sobre flexibilidade educacional, com foco na Educação a Distância

Antes de tecer qualquer comentário sobre os dados da Tabela 1, merecem aqui duas ressalvas:

- Foram feitas buscas nas bases utilizando radicais e não apenas os termos exatos; assim, a busca por "espaç*", por exemplo, localizaria "espaço", "espaçamento" e "espaço escolar" ao mesmo tempo. Por isso, deixamos entre parênteses na tabela a quantidade de termos distintos logo à direita da quantidade de aparição do radical (ex.: o termo "Currículo" apareceu 129 vezes em 21 diferentes expressões: currículo oculto, teorias do currículo etc.).

- Pelo escopo desse texto, não foi feita uma busca refinada por exclusão. Assim, é possível e provável que um mesmo trabalho tenha dois ou mais termos apresentados na Tabela 1. Por exemplo, observamos que uma das teses trazia como palavra-chave o termo "espaço" e "tempo", o que duplica a mesma tese entre os 27 termos encontrados com "espaço" e entre as 40 ocorrências do termo "tempo". Ao final, foram levantados 266 artigos e 165 teses para análise de títulos, resumos e palavras-chave associadas. 


\section{Aspectos analíticos e interpretativos: resultados quali-quantitativos}

Como resultados, essa quantificação dos trabalhos publicados em artigos e teses com os descritores selecionados nesta investigação (Tabela 1) indicou que:

- Nenhum dos trabalhos da base trata diretamente da flexibilidade na EaD e nem mesmo da flexibilidade no ensino-aprendizagem. Isto já denuncia a pouca importância que a temática tem recebido por pesquisadores da educação. No geral, observa-se que aproximadamente 10\% dos artigos e uma média de quase $14 \%$ das teses tratam direta ou indiretamente de algum dos descritores eleitos para busca.

- Individualmente, os termos que mais se aproximariam da temática central seriam flexível/flexibilidade, u-learning/m-learning ou ainda educação aberta/personalização do ensino-aprendizagem. Todavia, observa-se pela Tabela 1 que nenhuma tese e praticamente nenhum artigo trata dessas temáticas. Os três artigos que trazem o descritor "flexível" tratam de organização flexível do trabalho. Também o descritor "flexibilidade" aparece em quatro artigos, sendo dois deles os mesmos com termo-chave "flexível". Os outros dois trabalhos tratam de flexibilidade corporal e flexibilidade na legislação.

- Em relação ao Bloco B (modalidade de EaD e seus tipos), observa-se grande concentração dos trabalhos tratando do termo Educação a Distância, o que consideramos adequado. Os outros termos são tipos de Educação a Distância e não substituem a modalidade em si. Foram identificadas 14 teses e 17 artigos sobre o Bloco B, mas apenas uma tese traz em seu título "educação online" e mais uma com "b-learning" (abreviatura para blended learning em português, aprendizagem híbrida ou educação mista, pela coexistência de $\mathrm{EaD}$ com educação presencial). Além disso, o descritor "Educação a Distância" apareceu em 57 dos trabalhos, ao passo somando-se todos os outros tipos de EaD, temos 30 ocorrências.

- Os outros descritores não apresentam surpresa ou exigem atenção especial exceto pelos termos disciplina, agenda e lugar, que apareceram na maioria das vezes com significados diversos do que buscávamos.

Enfim, a análise quantitativa dos dados atende ao objetivo proposto: demonstrar a carência (e, por conseguinte a necessidade e importância de investigações nesta área) de estudos envolvendo a flexibilidade na EaD. Consideramos que, em 
decorrência da falta de pesquisas e conhecimentos detalhado sobre as peculiaridades das configurações possíveis para o ensino-aprendizagem na EaD, muitas vezes os gestores/educadores buscam estratégias equivocadas ou inadequadas na modelagem do sistema de EaD. Somando-se a outros trabalhos que desejam auxiliar nessa melhor compreensão da flexibilidade no ensino-aprendizagem, este texto busca revelar a temática, suas lacunas e sua relevância para constituir uma proposta de $\mathrm{EaD}$ mais adequada. Por isso, um tratamento dos dados de modo pormenorizado e qualitativo poderia dar outras pistas. Nesse sentido, filtramos os trabalhos para análise mais detalhada, como se segue.

Após quantificar os termos, relacionamos todas as teses e artigos que tinham em seu título algum dos descritores da pesquisa. Depois de analisar os títulos e o conjunto de palavras-chave das 165 teses e dos 266 artigos selecionados (Tabela1), percebemos que a maioria deles tinha como foco uma temática completamente distinta dos assuntos flexibilidade espacial, flexibilidade temporal ou flexibilidade pedagógica. Assim, após verificação cuidadosa de cada tese e artigo (pelos títulos e palavras-chave), foram selecionadas as 23 teses e os 25 artigos com foco mais aproximados do nosso interesse e, então, analisamos qualitativamente também os títulos e resumos desses trabalhos. Ao final das análises, apesar de nenhum trabalho tratar especificamente da temática flexibilidade na $\mathrm{EaD}$, foram escolhidos as quatro teses (Quadro 1) e os nove artigos (Quadro 2) com discussões mais aproximadas do foco deste texto. Em seguida, analisamos com mais detalhes o conteúdo de cada trabalho.

\begin{tabular}{|l|l|c|c|}
\cline { 2 - 4 } \multicolumn{1}{c|}{ Título da tese } & $\begin{array}{c}\text { Autor da } \\
\text { Tese }\end{array}$ & Instituição \\
\hline $\mathbf{1}$ & $\begin{array}{l}\text { A interdisciplinaridade na ação de projetar ambientes } \\
\text { virtuais de aprendizagem: o caso dos projetos do } \\
\text { NUTED/UFRGS }\end{array}$ & Leite (2008) & UFRGS \\
\hline $\mathbf{2}$ & $\begin{array}{l}\text { Educação a distância e trabalho docente virtual: sobre } \\
\text { tecnologia, espaços, tempos, coletividade e relações } \\
\text { sociais de sexo na Idade Mídia }\end{array}$ & Mill (2006) & UFMG \\
\hline $\mathbf{3}$ & $\begin{array}{l}\text { Interdisciplinaridade na educação a distância: estudo } \\
\text { de caso no âmbito de um curso de pedagogia }\end{array}$ & $\begin{array}{c}\text { Charczuk } \\
\text { (2012) }\end{array}$ & UFRGS \\
\hline $\mathbf{4}$ & $\begin{array}{l}\text { Práticas pedagógicas e espaços informacionais } \\
\text { da universidade: possibilidades de integração na } \\
\text { construção do espaço crítico }\end{array}$ & $\begin{array}{l}\text { Gomes } \\
\text { (2006) }\end{array}$ & UFBA \\
\hline
\end{tabular}

Quadro 1. Relação de teses com temáticas mais aproximadas das flexibilidades espacial, temporal e curricular 


\begin{tabular}{|c|c|c|c|}
\hline & Autoria & Título do Artigo & Revista/Edição \\
\hline $\mathbf{1}$ & Parente (2010) & A construção dos tempos escolares & $\begin{array}{l}\text { Educ. em } \\
\text { Revista, v.26, } \\
\text { n.2, p.135-156 }\end{array}$ \\
\hline 2 & Quadros (2010) & $\begin{array}{l}\text { A percepção de professores e estudantes sobre } \\
\text { a sala de aula de ensino superior: expectativas e } \\
\text { construção de relações no curso de química da } \\
\text { UFMG }\end{array}$ & $\begin{array}{l}\text { Ciência e } \\
\text { Educação, v.16, } \\
\text { n.1, p.103-114 }\end{array}$ \\
\hline 3 & $\begin{array}{l}\text { Soares et al. } \\
(2011)\end{array}$ & $\begin{array}{l}\text { Convivência e aprendizagem em ambientes } \\
\text { virtuais: uma reflexão a partir da biologia do } \\
\text { conhecer }\end{array}$ & $\begin{array}{l}\text { Educ. em } \\
\text { Revista, v.27, n.3, } \\
\text { p.39-59 }\end{array}$ \\
\hline 4 & Macedo (2006) & $\begin{array}{l}\text { Currículo como espaço-tempo de fronteira } \\
\text { cultural }\end{array}$ & $\begin{array}{l}\text { Rev. Bras. Educ., } \\
\text { v.11, n.32, p.285- } \\
296\end{array}$ \\
\hline 5 & $\begin{array}{l}\text { Amarilla Filho } \\
(2011)\end{array}$ & $\begin{array}{l}\text { Educação a distância: uma abordagem } \\
\text { metodológica e didática a partir dos ambientes } \\
\text { virtuais }\end{array}$ & $\begin{array}{l}\text { Educ. em } \\
\text { Revista, v.27, n.2, } \\
\text { p.41-72 }\end{array}$ \\
\hline 6 & Torres (2007) & $\begin{array}{l}\text { Laboratório on-line de aprendizagem: uma } \\
\text { experiência de aprendizagem colaborativa por } \\
\text { meio do ambiente virtual de aprendizagem } \\
\text { Eurek@Kids }\end{array}$ & $\begin{array}{l}\text { Cadernos } \\
\text { CEDES, v.27, } \\
\text { n.73, p.335-352 }\end{array}$ \\
\hline 7 & $\begin{array}{l}\text { Barros et al. } \\
(2011)\end{array}$ & $\begin{array}{l}\text { O currículo do Curso Técnico em Agropecuária: } \\
\text { subvertendo a concepção de grade curricular }\end{array}$ & $\begin{array}{l}\text { Educ. e Pesquisa, } \\
\text { v.37, n.2, p.375- } \\
388\end{array}$ \\
\hline 8 & $\begin{array}{l}\text { R o b e r t s o n } \\
(2009)\end{array}$ & $\begin{array}{l}\text { O processo de Bolonha da Europa torna-se } \\
\text { global: modelo, mercado, mobilidade, força } \\
\text { intelectual ou estratégia para construção do } \\
\text { Estado? }\end{array}$ & $\begin{array}{l}\text { Rev. Bras. Educ., } \\
\text { v.14, n.42, p.407- } \\
422\end{array}$ \\
\hline 9 & Thiesen (2011) & $\begin{array}{l}\text { Tempos e espaços na organização curricular: } \\
\text { uma reflexão sobre a dinâmica dos processos } \\
\text { escolares }\end{array}$ & $\begin{array}{l}\text { Educ. em } \\
\text { Revista, v.27, n.1, } \\
\text { p.241-26o }\end{array}$ \\
\hline
\end{tabular}

Quadro 2. Relação de artigos com temáticas mais aproximadas das flexibilidades espacial, temporal e curricular

Em relação às quatro teses selecionadas, observamos que, cada uma por seu lado, todas contribuem parcialmente para compreender a flexibilidade na EaD. Todavia, nenhuma tese, por si só, dá conta da temática. Abaixo, segue uma breve síntese analítica de cada uma delas.

Na primeira tese, Leite (2008) estuda a interdisciplinaridade na ação de projetar Ambientes Virtuais de Aprendizagem (AVA) numa perspectiva piagetiana. A pesquisa aborda o jogo entre forma e conteúdo que caracteriza a ação de projetar e a 
interdisciplinaridade, com base nas categorias de análise: relações interdisciplinares, criação de novidades e cooperação entre os projetistas. Todavia, a tese não trata de flexibilidade pedagógica, como era suposto. A abordagem interdisciplinar é base para uma proposta pedagógica flexível e dinâmica, mas a perspectiva de análise do texto volta-se para a construção de um AVA que possibilite a interdisciplinaridade. Por outro lado, o foco da tese está também nos AVA, que é uma das ferramentas indispensáveis para uma proposta de EaD efetivamente flexível. Isto é, Leite (2008) trata apenas de um pequeno fragmento do que deve ser uma perspectiva de análise pela flexibilidade na EaD... de todo modo, já é um passo.

Na segunda tese, Charczuk (2012) investiga, no âmbito do currículo e das práticas pedagógicas, como a interdisciplinaridade se desenvolve nas relações estabelecidas entre disciplinas e diversos profissionais que se engajam em práticas pedagógicas na EaD. Concebendo a interdisciplinaridade como a colaboração entre diversas disciplinas que conduz a interações e possibilita reciprocidade nas trocas, favorecendo um enriquecimento mútuo entre disciplinas envolvidas. Nesse sentido, analisa-se a articulação dos componentes curriculares para além da divisão em disciplinas fechadas e a participação de vários profissionais de diversas áreas no compartilhamento das interdisciplinas e elaboração das atividades. Uma contribuição interessante desta tese é que, segundo Charczuk (2012), as análises realizadas possibilitaram reflexões sobre a necessidade de o currículo prever espaços de permeabilidade entre conteúdos e profissionais que atuam na $\mathrm{EaD}$ a fim de fomentar práticas interdisciplinares. Para isso, a cooperação entre os profissionais foi identificada como um fator importante para a efetivação de tais práticas. Entendendo que a flexibilidade pedagógica abarca maleabilidade para estudantes e também para educadores, é importante registrar esse indicativo da necessidade de aproximação entre profissionais. Igualmente importante, é notar a necessidade de indução da interdisciplinaridade e permeabilidade dos componentes curriculares, das relações de troca entre docentes e, portanto, da flexibilidade.

A terceira tese Mill (2006) trata dos tempos e espaços escolares, que constituem fatores fundantes para a compreensão do processo de trabalho pedagógico. Considerando o espaço da secular sala de aula (historicamente compreendida como lugar privilegiado para o ensino-aprendizagem e para a atuação docente) e os emergentes ambientes virtuais de aprendizagem (ambiente para ensinoaprendizagem simulado telemática), a pesquisa propõe reflexões sobre as condições de vida dos trabalhadores virtuais da EaD. Ao menos indiretamente, os espaços e tempos da cibercultura são tratados, nesta tese, como formas de flexibilização do ensino-aprendizagem. Os AVA são assim, uma simulação dos tradicionais ambientes 
educacionais, agregando, todavia, mais valor aos espaços e tempos da educação por torná-los mais flexíveis e dinâmicos. Apesar disso, nesta tese, Mill (2006) não trata da perspectiva pedagógica da flexibilidade na $\mathrm{EaD}$, direcionando seu foco para a perspectiva docente do processo.

Na quarta e última tese, Gomes (2006) objetivou identificar a possibilidade de interseção do ambiente da sala de aula aos ambientes da biblioteca e do laboratório num processo dialógico favorável à construção do espaço crítico pelo desenvolvimento de ações articuladas. Esperávamos que esta pesquisa pudesse trazer contribuições para o entendimento da flexibilidade espacial (e temporal) da educação, pois propunha múltiplos lugares e momentos de aprendizagem. Todavia, os resultados da própria pesquisa indicam que cada espaço (sala de aula, biblioteca e laboratório de informática) limita-se no seu foco tradicional; isto é, permanecem atuando isoladamente, com metas específicas, sem integração entre si e sem grandes transformações. O trabalho de Gomes (2006) aponta um indício das dificuldades de implementação da efetiva flexibilidade espacial, temporal ou pedagógica.

Pela análise dos títulos e palavras-chave dos artigos, três em especial nos chamaram a atenção. No Quadro 2, são os textos de Thiesen (2011), Parente (2010) e Macedo (2006). Por isso, trataremos primeiro desses três artigos e, em seguida, comentaremos também os outros artigos.

O primeiro artigo, "Tempos e espaços na organização curricular: uma reflexão sobre a dinâmica dos processos escolares”, de Thiesen (2011), propõe uma reflexão sobre os conceitos de tempo e espaço na organização curricular com ênfase na dinâmica dos processos escolares, partindo da concepção modernista dessas categorias. Apontando algumas críticas já feitas a essa concepção, o texto argumenta em defesa de uma releitura dos conceitos tempo, espaço e organização curricular na contemporaneidade. Uma releitura passível de tradução em mudanças significativas nas formas de organização curricular na atualidade. Thiesen (2011) nos apresenta outro indicativo interessante quando observa que a releitura dos conceitos de tempo e espaço curricular está sendo estimulada em contextos que incluem a democratização da informação via internet, a globalização econômica, o desenvolvimento das tecnologias da informação e comunicação, a expansão da $\mathrm{EaD}$ e, muito expressivamente, as contribuições trazidas pelas atuais abordagens sobre currículo e sobre infância.

No texto "A construção dos tempos escolares" Parente (2010) analisa a concepção de tempo, considerando sua construção sócio-histórica e cultural. Apresenta algumas heranças dos tempos escolares, mostrando que estes são construções humanas 
e, por isso mesmo, passíveis de transformações. Ao apresentar a abrangência da noção de tempos escolares (tempos de escola, tempos de escolarização e tempos na escola), o estudo de Parente (2010) incita a busca de inovações políticas e escolares que produzam alternativas aos tempos escolares vigentes e indica a necessidade de construir tempos escolares mais humanos, mais atentos às necessidades dos sujeitos da educação.

Esta sugestão de construção de tempos mais adequados aos sujeitos da educação é uma das grandes riquezas deste artigo para a flexibilização da EaD. Como dissemos, na base da $\mathrm{EaD}$ está a noção de democratização do conhecimento e atendimento personalizado aos estudantes. Isto é, adaptação dos estudos aos tempos, espaços e condições de aprendizagem dos sujeitos.

No terceiro texto que destacamos, intitulado "Currículo como espaço-tempo de fronteira cultural”, Macedo (2006) defende que o currículo precisa ser pensado como espaço-tempo de fronteira entre culturas, garantindo a centralidade da categoria cultura em detrimento do conhecimento, caro à pedagogia crítica e ainda hoje embasando as discussões do campo. No texto, o currículo é tratado de modo amplo e como entre-lugar cultural. Todavia, o artigo não apresenta contribuições especiais para entendermos a flexibilidade em nenhuma das perspectivas do nosso interesse, quais sejam: flexibilidade espacial, temporal e pedagógica.

Os outros seis textos selecionados também prometiam mais do que de fato contribuíram para o entendimento de aspectos da flexibilidade na EaD. Entretanto, direta ou indiretamente e mesmo que parcialmente, todos auxiliam no nosso estudo, pois tangenciam os aspectos tempo, espaço e/ou organização curricular e, por isso mesmo, também merecem uma breve descrição e análise.

Comecemos pelo texto de Robertson (2009), que trata da mobilidade dos estudantes europeus em função do processo de Bolonha. Esse processo representa um marco no processo de mobilidade estudantil e flexibilidade (espacial, temporal e pedagógica). O Processo Multilateral de Bolonha foi projetado para criar uma arquitetura unificada de educação superior na Europa. Após sua implantação, os estudantes ganharam maior liberdade de circulação e personalização da sua formação, com maior flexibilização e personalização dos estudos. Sabendo disso, selecionamos o texto "O processo de Bolonha da Europa torna-se global: modelo, mercado, mobilidade, força intelectual ou estratégia para construção do Estado?” que examina a interligação progressiva dos espaços da política de educação superior na Europa, abarcando o seu projeto de globalização da educação superior. Entretanto, observamos que o texto traz uma análise política e demográfica, com 
foco em questões inter-regionais. A análise da flexibilidade pedagógica ou curricular e espacial, que esperávamos, não foi feita.

O artigo de Soares et al. (2011), "Convivência e aprendizagem em ambientes virtuais: uma reflexão a partir da biologia do conhecer", busca compreender como um ambiente virtual pode se constituir num domínio de convivência capaz de propiciar a aprendizagem, como dimensão complexa e sistêmica do processo educativo. $O$ texto pressupõe que ambientes virtuais de aprendizagem podem se constituir em domínios de ações que levem à autorregulação e a transformações estruturais. Em primeira instância, a análise do texto diverge bastante do nosso interesse pela flexibilidade espacial, temporal e pedagógica. Entretanto, vale destacar que o artigo traz como conclusão que os ambientes de aprendizagem possibilitam a emergência de fluxos de interações que contribuam para que se estabeleça a convivência. Sabemos que esses fluxos de interações e de convivência são essenciais para aumentar as possibilidades de mobilidade do estudante, de personalização da formação e de flexibilidade em sentido amplo.

No artigo "Educação a distância: uma abordagem metodológica e didática a partir dos ambientes virtuais" Amarilla Filho (2011) aborda a EaD a partir da influência dos ambientes virtuais, considerando as suas implicações para o processo de ensino-aprendizagem. Esperávamos que o texto abordasse também as influências e possibilidades técnicas dos ambientes virtuais para maiores flexibilidades espacial, temporal e pedagógica. Todavia, o artigo se atém mais às influências das tecnologias digitais sobre a prática pedagógica. Há contribuições para a nossa análise, mas não tantas quanto esperávamos.

Por seu turno, Quadros (2010) analisou as percepções de estudantes e professores acerca das relações que se desenvolvem em sala de aula, considerando-a como espaço de formação humana, marcado pelas relações subjetivas e constituído pela diversidade e heterogeneidade. O título do trabalho - "A percepção de professores e estudantes sobre a sala de aula de ensino superior" - chamou a atenção, pelo foco na nossa análise na flexibilidade, pela proposição de compreensão da sala de aula. Como vimos, a sala de aula é um espaço de formação por excelência, permeado por tempos e relações pedagógicas. Há em cada sala de aula maior ou menor limitação da liberdade de ensino-aprendizagem. Podemos dizer que a sala de aula é, em si, a melhor representação da antiflexibilidade espacial, temporal e pedagógica. Ou seja, na educação presencial a sala de aula constitui limites e fronteiras de espaços e tempos da aprendizagem. Frustrando as nossas expectativas, o texto não trouxe contribuições significativas para compreender os tempos e espaços a serem 
flexibilizados. Seu foco volta-se para questões de negociações e afetividade entre professor e alunos.

Pelo seu foco no "desmanchar" das grades curriculares, selecionamos o artigo de Barros et al. (2011): "O currículo do Curso Técnico em Agropecuária: subvertendo a concepção de grade curricular”. Esperávamos uma análise da flexibilidade da matriz curricular. $\mathrm{O}$ texto analisa os fatores que influenciaram a composição do currículo, buscando compreender a forma como se dão as modificações (e suas fontes) no currículo de um curso. O desenrolar da análise proposta toma rumos bastante distintos dos que esperávamos, apesar do importante destaque dado ao "como as modificações curriculares são incorporadas na prática de ensino dos professores".

Também com foco nos ambientes virtuais de aprendizagem, o artigo de Torres (2007) foi selecionado pela proposta de análise de um laboratório virtual - que são importantíssimos para redução das limitações espaçotemporais. O estudo apresenta o ambiente virtual de aprendizagem denominado Eurek@Kids, que permite o desenvolvimento de propostas de aprendizagem colaborativas. O texto apresenta ainda uma proposta metodológica de aprendizagem colaborativa, denominada Laboratório On-Line de Aprendizagem. Apesar das expectativas em relação ao texto, ele contribuiu muito pouco para o foco da nossa análise; isto é, o texto trata pouco ou nada dos aspectos temporais, espaciais ou pedagógicos da flexibilidade na educação.

\section{OUTRAS CONSIDERAÇÕES, NÃO CONCLUSIVAS, SOBRE A FLEXIBILIDADE EDUCACIONAL}

Enfim, podemos dizer que as análises quali-quantitativas denunciam a escassez de publicações voltadas para o melhor entendimento dos diversos aspectos da flexibilidade na EaD. Observamos não há qualquer artigo ou tese com foco específico na flexibilidade pedagógica/curricular ou espaçotemporal do ensino-aprendizagem. Além disso, observamos que são poucos artigos e poucas teses que tangenciam a referida temática e, mesmo assim, trazem apenas contribuições parciais para o entendimento do importante aspecto flexibilidade na EaD. Claramente, serão bem-vindas propostas investigativas interessadas na interpretação do fenômeno flexibilidade educacional.

Nesse contexto, a configuração de um modelo pedagógico maleável em termos de onde (espaço), quando (tempo) e como (organização curricular) ocorre o ensinar e o aprender desperta o desejo de educadores e educandos por estruturas educacionais mais adequadas à nossa época. Esse desejo se realiza no âmbito da cibercultura, que tem exigido e possibilitado propostas de ensino-aprendizagem 
mais flexíveis e personalizáveis, capazes de atender às particularidades de cada sujeito envolvido e às suas condições de vida, trabalho ou de estudos. Podemos dizer que tal desejo objetiva-se por meio de iniciativas de educação virtual (seja na EaD ou na educação presencial com uso intensivo de tecnologias digitais), o que na literatura da área recebe apelidos como educação flexível, híbrida, virtual, aberta e, no inglês, m-learning, u-learning, b-learning entre outros termos.

Por exemplo, a noção de educação híbrida (b-learning ou blended learning) tem suas bases na busca de maior flexibilidade, num movimento entre o ensinoaprendizagem tradicional, majoritaria e tipicamente presencial, e o ensinoaprendizagem integralmente virtual. A matriz de configuração do b-learning é, geralmente, representada por um diagrama como mostra a Figura 2.

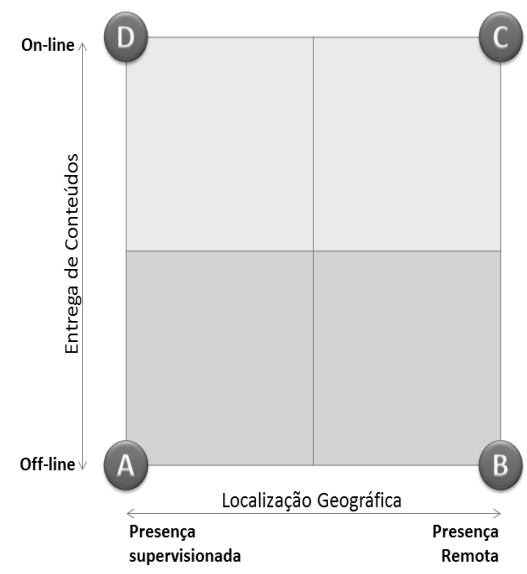

Figura 2. Proposta de matriz analítica para o blended-learning (educação híbrida)

Fonte: adaptado de Staker et al. (2011, p.6).

Com base nessa proposta de b-learning da Figura 2, sugerimos outra matriz (Figura 3), mais genérica, para analisar o grau de flexibilidade de um modelo pedagógico. Observa-se um movimento que vai da educação massificada, marcada pela padronização dos processos, até propostas educacionais mais individualizadas e personalizadas. 


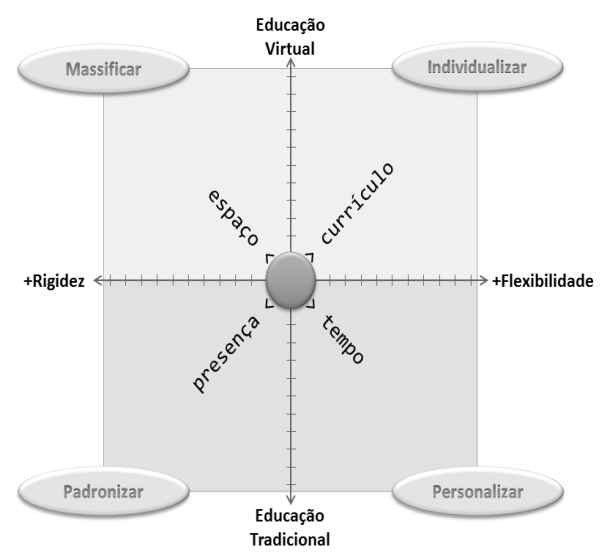

Figura 3. Proposta de matriz analítica para a flexibilidade pedagógica

Enfim, desde que a aprendizagem ocorra, os tempos e espaços que caracterizam os contemporâneos adjetivos da educação (presencial ou distância) devem ser compreendidos como diversidade e riqueza das possibilidades de atendimento a públicos distintos, em condições mais (ou menos) adequadas ou (des)favoráveis.

Como indica a Figura 3, uma proposta pedagógica pode ser mais flexível ou mais rígida, seja em termos de espaço, tempo e currículo. A noção de presença instala-se em conjunto com esses outros três termos e transforma a percepção tradicional de lugares e momentos de ensinar e aprender, além de propor uma revisão da organização curricular da educação presencial. Seja para uma educação mais tradicional ou mais inovadora - configurada como educação presencial, como Educação a Distância (tradicional ou virtual) ou como modelo blended learning (híbrido de modelos presencial e virtual) - há implícito o esforço de educadores para configurar propostas mais personalizadas/individualizadas e menos padronizadas/ massificadas.

Enfim, aos interessados nessa temática flexibilidade pedagógica, sugere-se consulta aos resultados de uma investigação de Mill e Carmo (2013), que fazem uma análise comparativa das características de flexibilidade pedagógica em modelos públicos de EaD portugueses e brasileiros. Observou-se que, na prática, é difícil e complexo implementar a flexibilidade educacional. Observou-se também que cada modelo possui certa parcela de rigidez (assim como de flexibilidade). Portanto, em termos de flexibilização educacional, um modelo pedagógico é melhor analisado e caracterizado numa perspectiva de escalas - como o cinza, que vai do branco ao preto; 
a flexibilidade educacional vai do rígido/inflexível ao maleável/adaptável. Sendo assim, os autores observaram que há diversos aspectos dos modelos portugueses que podemos incorporar nos sistemas de EaD do Brasil. Se o objetivo fosse a melhoria dos sistemas de $\mathrm{EaD}$ portugueses à luz das experiências brasileiras, certamente muitos outros elementos de flexibilidade educacional podiam ser "exportados" e agregados no ensino-aprendizagem de além-mar. Outros detalhes interessantes são apresentados no trabalho de Mill e Carmo (2013), contribuindo para o entendimento buscado neste texto; ou seja, quão flexível tem sido a $\mathrm{EaD}$ e, também, quais tipos de flexibilidade essa modalidade dá conta.

Nesse sentido, a educação virtual seria, portanto e apenas, uma variação da educação tradicional, para além das distâncias. As diferenças básicas de uma modalidade para outra residem, quase que exclusivamente, nesses aspectos temporais, espaciais e curriculares. As ricas possibilidades de flexibilização desses tempos, espaços e matriz curricular promovidas pelas tecnologias digitais de informação e comunicação transformam as formas de relacionar e de comunicar. A presença de professores e alunos muda sua natureza em função de novos espaçotempos e de organizações curriculares diferenciadas. Sem muita pretensão, apresentamos neste texto algumas contribuições para aqueles interessados em pensar a educação em termos de flexibilidade pedagógica e respeito ao ritmo de aprendizagem dos estudantes. Fica o convite para outros pesquisadores, para que busquem suprir lacunas nesta seara.

\section{NOTAS}

1. Trabalho resultante de pesquisa financiada pelas agências de fomento CAPES e $\mathrm{CNPq}$, às quais agradecemos pelo apoio.

2. Para uma análise crítica das implicações adversas dos tempos e espaços da educação virtual, ver Mill (2012).

3. A Base Teses PPGE do Grupo Horizonte da UFSCar considerou oito Programas de Pós-Graduação em Educação de importantes universidades públicas brasileiras: UFBA, UFMG, UFPR, UFRGS, UFRN, UFSCar, UnB e USP. Nesta base, foram consideradas apenas as teses disponíveis na internet até o segundo semestre de 2012, compreendendo o período de 2001 a 2012.

4. ABase Periódicos do Grupo Horizonte catalogou textos disponibilizados virtualmente, em Scielo.org, até o segundo semestre de 2012 por 11 periódicos classificados como A1 ou A2: Cadernos CEDES, Cadernos de Pesquisa, Ciência e Educação, Educação \& Sociedade, Educação e Pesquisa, Educação em Revista, Revista Ensaio, Estudos Avançados, Pró-Posições, Revista Brasileira de Educação e Tempo Social. 
5. Considerando o foco deste texto, foi feita apenas uma consulta simples. O Grupo Horizonte está fazendo análises mais detalhadas (quali-quantitativa) das produções científicas na EaD. Em breve, serão liberados os relatórios da investigação e artigos daí decorrentes.

\section{REFERÊNCIAS BIBLIOGRÁFICAS}

Amarilla Filho, P. (2011). Educação a distância: uma abordagem metodológica e didática a partir dos ambientes virtuais. Educ. em Revista, 27 (2), (41-72).

Barros, F. M.; Fiuza, A. L.; Barreto, M. L.; Ferreira Neto, J. A. (2011). O currículo do Curso Técnico em Agropecuária: subvertendo a concepção de grade curricular. Educ. e Pesquisa, 37 (2), (375-388).

Brasil, (2007). Ministério da Educação, Secretaria de Educação a Distância. Referenciais de qualidade para educação superior a distância. Brasília: MEC-SEED.

ForGRAD, (2003). Fórum Nacional de Pró-Reitores de Graduação das Universidades Brasileiras. Concepções $e$ Implementação da Flexibilização Curricular. Documento síntese das discussões dos Grupos de Trabalho do FORGRAD-2003. Campo Grande-MS: FORGRAD.

Charczuk, S. B. (2012). Interdisciplinaridade na educação a distância: estudo de caso no âmbito de um curso de pedagogia. Tese (Doutorado em Educação), Universidade Federal do Rio Grande do Sul - UFRGS.

Doctors, M. (org.), (2003). Tempo dos tempos. Rio de Janeiro: Jorge Zahar.

Elias, N. (1998). Sobre o tempo. Rio de Janeiro: Jorge Zahar.

Frago, A.V.; Escolano, A. (2001). Currículo, espaço e subjetividade: a arquitetura como programa. Rio de Janeiro: DP\&A.

Gomes, H. F. (2006). Práticas pedagógicas $e$ espaços informacionais $d a$ universidade: possibilidades de integração na construção do espaço crítico. Tese (Doutorado em Educação), Universidade Federal da Bahia - UFBA.

Harvey, D. (2009). Condição pós-moderna. 18.ed. São Paulo: Loyola.

Houaiss, A. (2001). Dicionário Eletrônico da Língua Portuguesa. Rio de janeiro: Editora Objetiva.

Leite, S. P. (2008). A interdisciplinaridade na ação de projetar ambientes virtuais de aprendizagem. Tese (Doutorado em Educação), Universidade Federal do Rio Grande do Sul - UFRGS.

Macedo, E. (2006). Currículo como espaçotempo de fronteira cultural. Rev. Bras. Educ., 11 (32), (285-296).

Mill, D. (2006). Educação a distância e trabalho docente virtual: sobre tecnologia, espaços, tempos, coletividade e relações sociais de sexo na Idade Mídia. Tese (Doutorado em Educação), Universidade Federal de Minas Gerais UFMG.

Mill, D. (2012). Docência virtual: uma visão crítica. Campinas: Papirus.

Mill, D.; Brito, N. D.; Silva, A. R. (2012). Sala de Aula Virtual: novos lugares e novas durações para o ensinar e o aprender na contemporaneidade. In: Oliveira, M.O.; Pesce, L. (org.). Educação e cultura midiática, 1. Salvador: EDUNEB, (169192).

Mill, D.; Carmo, H. (2013). Gestão estratégica de sistemas de educação a distância no Brasil e em Portugal: a propósito da flexibilidade educacional. Educação $e$ Sociedade (prelo).

Moore, M. G.; Kearsley, G. (2008). Educação a distância: uma visão integrada. São Paulo: Cengage learning. 
Parente, C. M. (2010). A construção dos tempos escolares. Educ. em Revista, 26 (2), (135-156).

Quadros, A. L. (2010). A percepção de professores e estudantes sobre a sala de aula de ensino superior: expectativas e construção de relações no curso de química da UFMG. Ciência e Educação, $16(1),(103-114)$.

Robertson. S. L. (2009). O processo de Bolonha da Europa torna-se global: modelo, mercado, mobilidade, força intelectual ou estratégia para construção do Estado? Rev. Bras. Educ., 14 (42), (407-422).

Rossel, P.; Bassand, M.; Roy, M. (1998). Au-delà du laboratoire: les nouvelles tecnologies à l'épreuve de l'usage. Lausanne: Presses Polytechniques.

Santos, M. (1999). A natureza do espaço: técnica e tempo, razão e emoção. 3. ed. São Paulo: Hucitec.

Silva, T. T. (2004). Documentos de identidade: uma introdução às teorias do currículo. 2.ed. Belo Horizonte: Autêntica.

Soares, E. M.; Valentini, C. B.; Rech, J. (2011). Convivência e aprendizagem em ambientes virtuais: uma reflexão a partir da biologia do conhecer. Educ. em Revista, 27 (3), (39-59).

Staker, H. et al. (2011). The rise of $K-12$ blended learning: profiles of emerging models. San Mateo: Innosight Institute. [en línea] Disponível em: www. innosightinstitute.org/innosight/wpcontent/uploads/2011/05/The-Rise-ofK-12-Blended-Learning.pdf (consulta 2013, 15 de julio).

Thiesen, J. S. (2011). Tempos e espaços na organização curricular: uma reflexão sobre a dinâmica dos processos escolares. Educ. em Revista, 27 (1), (241-260).

Torres, P. L. (2007). Laboratório on-line de aprendizagem: uma experiência de aprendizagem colaborativa por meio do ambiente virtual de aprendizagem Eurek@Kids. Cadernos CEDES, 27 (73), (335-352).

Tubella, I.; Gros, B.; Mas, X.; Macau, C. (2011). Flexible education: Analysing the changing demographic of online students at the Open University of Catalonia. eLearning Papers, 24, (1-11). [en línea] Disponível em: http://elearningpapers. eu/sites/default/files/media25537.pdf. (consulta 2013, 15 de julio).

\section{PERFIL ACADÉMICO Y PROFESIONAL DEL AUTOR}

Daniel Mill. Professor da Universidade Federal de São Carlos (UFSCar), onde trabalha como Docente e Gestor de Educação a Distância (EaD). Doutor em Educação pela UFMG, com pós-doutorado pela Universidade Aberta de Portugal. É membro de Programas de Pós-Graduação na UFSCar e Líder do Grupo Horizonte (Grupo de Estudos e Pesquisas sobre Inovação em Educação, Tecnologias e Linguagens). Como pesquisador, tem interesse particular pela interseção das temáticas: Trabalho Docente, Tecnologia, Linguagem, Aprendizagem e Educação a Distância.

E-mail: $\underline{\text { mill@ufscar.br - mill.ufscar@gmail.com }}$ 


\title{
DIRECCIÓN POSTAL DEL AUTOR
}

\author{
SEaD-UFSCar \\ Prof. Daniel Mill \\ Rod. Washington Luís, km 235 - SP-310 \\ 13565-905 - São Carlos - São Paulo
}

Fecha de recepción del artículo: 11/08/13

Fecha de aceptación del artículo: 17/10/13

\section{Como citar este artículo:}

Mill, D. (2014). Flexibilidade educacional na cibercultura: analisando espaços, tempos e currículo em produções científicas da área educacional. RIED. Revista Iberoamericana de Educación a Distancia, volumen 17, nº 2, pp. 97-126. 